\title{
Separation of Benzene-Cyclohexane Azeotropic Mixture through Polymeric Membranes with Microphase Separated Structures
}

\author{
Junichi TeradA, Tadashi HoHJOH, Shiro Yoshimasu, \\ Masahisa IKEMI, and Isao SHINOHARA \\ Department of Polymer Chemistry, Waseda University, \\ Ohkubo, Shinjuku-ku, Tokyo 160, Japan.
}

(Received September 30, 1981)

\begin{abstract}
Hydroxyethyl methacrylate (HEMA) (branch)-methyl acrylate (MA) (backbone) comb-type graft copolymers were synthesized by grafting an amino-semitelechelic oligo (HEMA) to a MA-glycidyl methacrylate (GMA) random copolymer. From electron microscope observation, it was found that these graft polymeric membranes had microphase separated structures. Pervaporation of a benzene-cyclohexane mixture through these membranes was carried out in order to study the effect of microphase separated structures on selective permeability. Benzene was found to preferentially permeate through the membranes. Moreover, the pervaporation rate of benzene increased with increasing MA mole fraction in the graft copolymers. It was found that the continuous phases of poly(MA) domains functioned as permeating pathways for benzene and that the selectivity of the graft polymeric membranes occurred in the process of dissolution of the solvent into the membranes. The microphase separated structure was found to effectively enhance the selectivity as a result of its suppressing the plasticizing effect of benzene.

KEY WORDS Pervaporation / Benzene-Cyclohexane Azeotropic Mixture / Membrane / Graft Copolymer / 2-Hydroxyethyl Methacrylate / Methyl Acrylate / Microphase Separated Structure/Plasticizing Effect / Separation/
\end{abstract}

Recently, the membrane separation technique has been found applicable to liquid mixtures which are difficult to separate or purify by distillation, solvent extraction, recrystallization, chromatography and other such means. ${ }^{1-5}$ Pervaporation is superior to such techniques as reverse osmosis and perextraction, since it does not require isolation of the permeate and can be applied to various organic liquid mixtures including water soluble organic liquids. However, this separation technique has not as yet been put to practical use because of the delay in the development of a membrane with high selective permeability. It is known that the selectivity of liquid mixtures through a membrane is a function of the difference in solubility of the solvents toward a membrane and diffusivity of a solvent in a membrane. ${ }^{6}$ It was found that the azeotropic mixture or a close-boiling mixture can be separated perfectly by using the difference in solubility of the solvents for the membrane. ${ }^{7,8}$

Generally, block or graft copolymers have mi- crophase separated structures due to the incompatibility of constituent chains. These microdomain structures depend on the composition of copolymers, the length of constituent chains, and the casting conditions. ${ }^{9}$ Thus, if continuous phases of microdomains in which only a selective solvent can dissolve, are formed to give permeating pathways from the upstream to the downstream side of a membrane, the membrane may display favorable selectivity. The diffusivity of the selective solvent may be affected by the morphology of the membrane, i.e., the size or the phase separation state of the microdomains.

In the present paper, in order to separate the benzene-cyclohexane azeotropic mixture, 2-hydroxyethyl methacrylate (HEMA) (branch)-methyl acrylate (MA) (backbone) comb-type graft copolymers were synthesized. Both solvents are insoluble in oligo(HEMA) and the selective solvent (benzene) has a high solubility toward poly(MA). Pervaporation of the benzene-cyclohexane mixture 
through this graft polymeric membrane was carried out, and the effect of the microdomain structure on selective permeability was studied.

\section{EXPERIMENTAL}

\section{Material}

$\alpha, \alpha^{\prime}$-Azobisisobutyronitrile (AIBN), 2-aminoethanethiol (AESH), $N, N$-dimethylformamide (DMF), MA and glycidyl methacrylate (GMA) were purified by conventional methods. HEMA was distilled under reduced pressure in a nitrogen atmosphere and the fraction having a boiling point of $87^{\circ} \mathrm{C} / 5 \mathrm{mmHg}$ was used. All other reagents and solvents were of extra pure grade.

\section{Synthesis of HEMA (branch)-MA (backbone) Comb Type Graft Copolymer}

Amino-semitelechelic HEMA oligomers as branch oligomers were prepared by a previously described procedure. ${ }^{10}$ MA-GMA random copolymers as backbone polymers were synthesized as follows. DMF solutions containing MA, GMA, and AIBN (as an initiator) were sealed by the conventional method, and polymerization was carried out at $60 \pm 0.1^{\circ} \mathrm{C}$ for a given period of time. The contents were then poured into a diethyl etherpetroleum ether mixture so as to precipitate the copolymers which were filtered and dried at reduced pressure.

An amino-semitelechelic HEMA oligomer (branch oligomer) was allowed to react with a MA-GMA random copolymer (backbone polymer) in DMF solvent at $50^{\circ} \mathrm{C}$ for $72 \mathrm{~h}$ under the condition such that [amino group]/[epoxy group] = $0.15-1.20$. The comb-type graft copolymers were purified by precipitation with 2-propanol in which branch oligomers were selectively soluble. The unreacted branch oligomers were removed from the reactant of graft copolymerization by the same procedure. The intrinsic viscosities of the graft copolymers were higher than those of the backbone polymers in $\mathrm{DMF}$ at $25^{\circ} \mathrm{C}$, indicating that the HEMA (branch)-MA (backbone) combtype graft copolymers were synthesized. The results of the graft copolymer preparation are given in Table I. It can be seen from this table that the MA mole fraction in the copolymer can be controlled by the molecular weight of the HEMA oligomer chains, the GMA mole fraction in backbone polymers and the concentration ratio of the functional groups.

Membranes were prepared by casting 7\% DMF solutions of the copolymers on a polyethylene substrate and by evaporating the solvent at $40^{\circ} \mathrm{C}$ for $48 \mathrm{~h}$. The membranes were then dried under reduced pressure for $24 \mathrm{~h}$. The average thickness of a membrane was about $40 \mu \mathrm{m}$.

\section{Morphology of Microdomains}

DMF solutions of the copolymers were made to flow on the carbone-coated collogion membranes, and thin films were prepared by evaporating the solvent at $40^{\circ} \mathrm{C}$. After drying under reduced pressure, the domain structures of the films were observed with an electron microscope (Hitachi HU-11D Type).

\section{Pervaporation Experiments}

The apparatus used for measuring the rates of pervaporation through the graft polymeric membranes is shown in Figure 1, and a cross section showing the details of the pervaporation cell is given in Figure 2. The cell was stainless steel. The upper compartment had a capacity of about $80 \mathrm{ml}$, and the membrane area in contact with the feed solution was about $5.7 \mathrm{~cm}^{2}$. The membrane was supported by filter paper resting on a sintered stainless disk. The feed solution was introduced into the upper compartment and vigorously stirred by a magnetic stirrer throughout the experiment. The lower compartment was evacuated to less than $5 \mathrm{mmHg}$, and the permeate was collected in a trap cooled by a dry icemethanol mixture. The composition and flux of the permeate were determined by gas chromatography (Shimadzu GC-3BT Type). Ethylbenzene served as

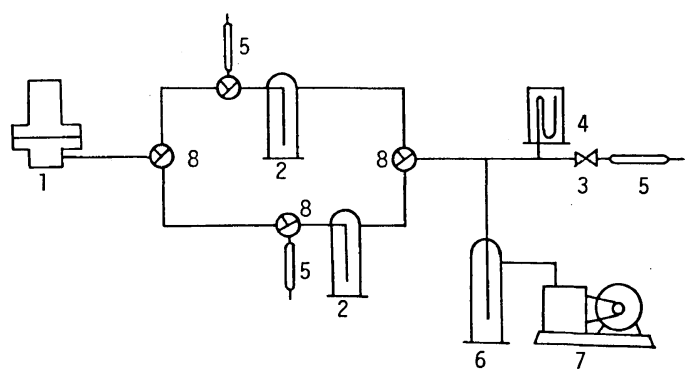

Figure 1. Exeperimental system for pervaporation experiments: 1 , pervaporation cell; 2 , traps; 3 , stopcoks; 4 , manometer; 5 , leaks; 6 , trap; 7 , vacuum pump; 8 , three ways cocks. 


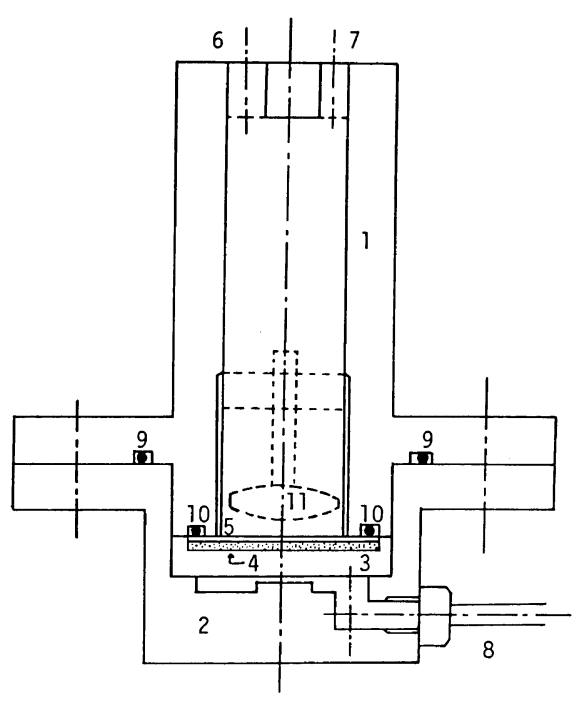

Figure 2. A pervaporation cell for pervaporation experiments: 1, upper compartment; 2, lower compartment; 3, steel disk supporter; 4, sintered stainless disk; 5 , polymeric membrane; 6 , thermometer holder; 7 , feed solution inlet; 8 , vapor outlet joint; 9, O-ring G-60; 10 , O-ring G-35; 11, magnetic stirrer.

the internal standard for the determination of the permeated benzene and cyclohexane. The feed solution was changed at equal time interval lapses so as to prevent any change in composition. All of these procedures were repeated until a steady-state permeability had been obtained at $25^{\circ} \mathrm{C}$. The downstream pressure dependence of the permeability was not investigated in these experiments. The selective permeability of a membrane was measured with respect to pervaporation rate and separation factor. Since the permeate flux is inversely proportional to membrane thickness, the pervaporation rate $P$ is defined as,

$$
P=\frac{w \cdot \theta}{a \cdot t}
$$

where $w, \theta, a$ and $t$ denote the permeate flux, the membrane thickness, the membrane area and time, respectively. The separation factor $\alpha$ is defined as,

$$
\alpha=\frac{P_{\mathrm{A}} / P_{\mathrm{B}}}{F_{\mathrm{A}} / F_{\mathrm{B}}} \text { A, benzene; } \mathrm{B}, \text { cyclohexane }
$$

where $P_{\mathrm{A}} / P_{\mathrm{B}}$ and $F_{\mathrm{A}} / F_{\mathrm{B}}$ denote the concentration ratios of the permeate and the feed solution, respectively.

\section{Sorption and Desorption Experiments}

Swelling Ratio. A piece of membrane was immersed in the solvent mixture at room temperature. When the sorption reached equilibrium, this piece was rapidly removed from the bottle, blotted to remove the surface solvent and placed on a weighing scale. The first reading was taken $40 \mathrm{~s}$ following removal of the membrane from the mixture, and four to five readings were made at $10 \mathrm{~s}$ intervals. The weight of the solvent-swollen-membrane was obtained by extrapolating the initial portion of the experimental curve to zero time. The swelling ratio $S$ is defined as,

$$
S=\frac{W_{\mathrm{s}}-W_{\mathrm{d}}}{W_{\mathrm{d}}}
$$

where $W_{\mathrm{d}}$ and $W_{\mathrm{s}}$ denote the weight of dry and solvent-swollen membranes, respectively. The diffusion coefficient $D$ was calculated as $P / S$.

Solvent Composition in the Membrane. Desorption experiments were carried out using the pervaporation apparatus after improving it. $^{7}$ The solvent-swollen-membrane was removed from the bottle and the surface solvent was blotted. The solvent in the membrane was allowed to evaporate under reduced pressure and collected in a cold trap. The composition of the solvent was determined by gas chromatography, and used to calculate the separation factor $\alpha_{\mathrm{s}}$ defined by,

$$
\alpha_{\mathrm{s}}=\frac{S_{\mathrm{A}} / S_{\mathrm{B}}}{F_{\mathrm{A}} / F_{\mathrm{B}}} \quad \text { A, benzene; B, cyclohexane }
$$

where $S_{\mathrm{A}} / S_{\mathrm{B}}$ and $F_{\mathrm{A}} / F_{\mathrm{B}}$ denote the concentration ratios of the solvent in the membrane and feed solution, respectively.

\section{RESULTS AND DISCUSSION}

\section{Morphology of Microdomains}

The film domain structures, without being stained, were observed with an electron microscope. Figure 3 shows the typical micrographs obtained. All membranes examined had microphase separated structures of the constituent chains. The dark portions are the spheres (island phases) dispersed in the bright matrix (sea phase) in G-2 and G-3, but the reverse of this applies in G-5 and G-7. The graft copolymers from G-1 to G-4 are HEMA-rich having MA mole fractions of $0.39-0.48$, and the copolymers from G-5 to G-10 are MA-rich having 


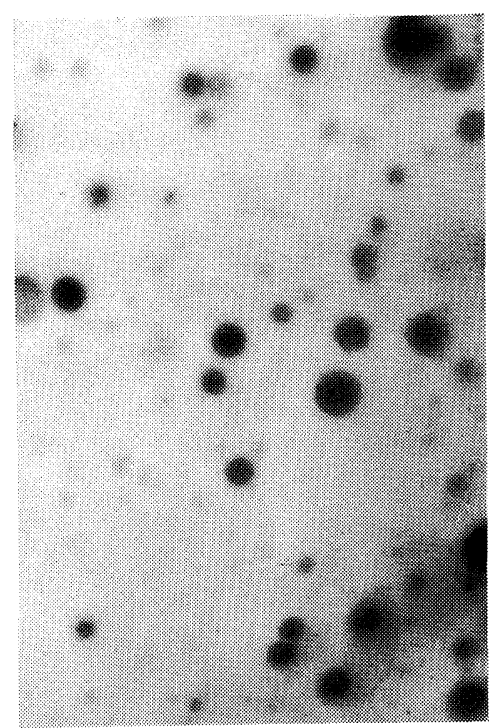

G-2

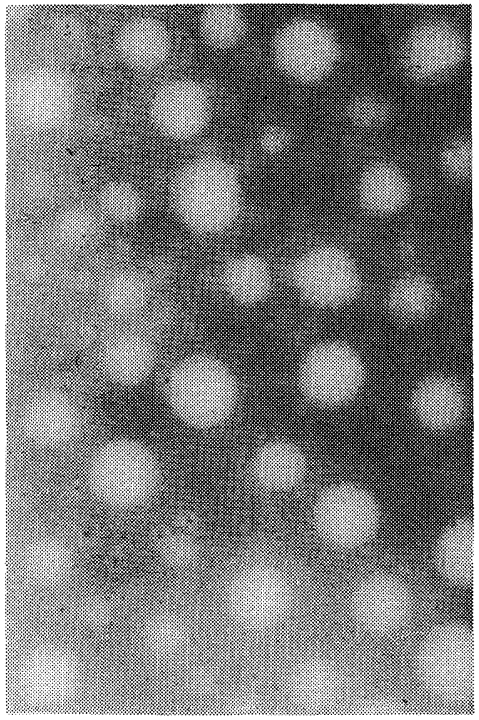

G-5

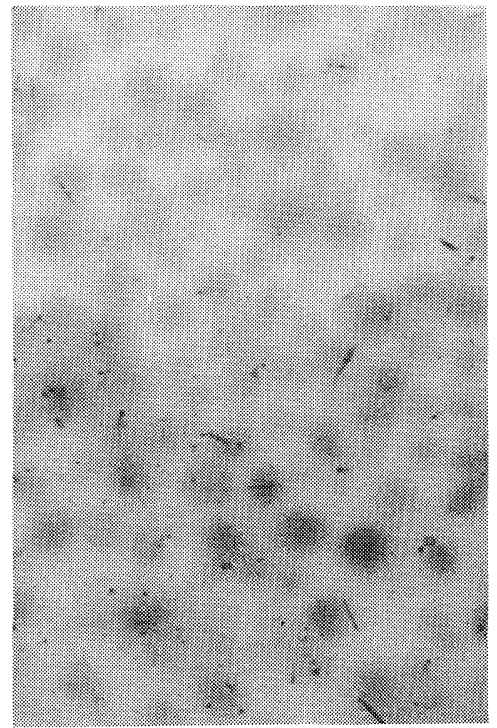

G-3

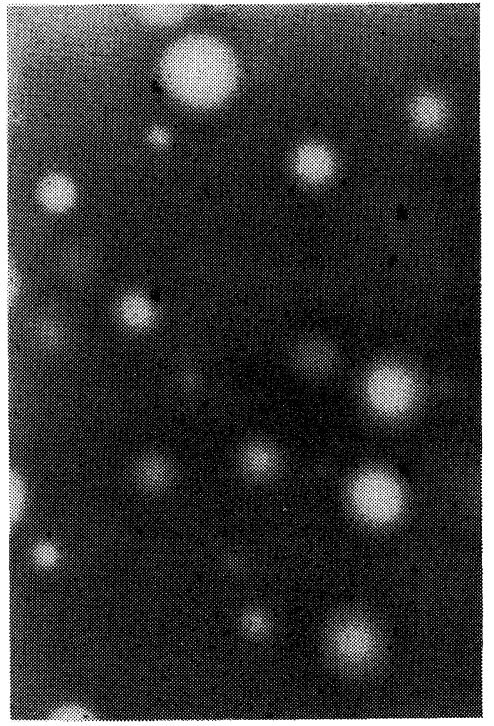

G-7

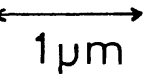

Figure 3. Electron micrographs of HEMA-MA comb type copolymer films cast from DMF at $40^{\circ} \mathrm{C}$.

MA mole fractions of $0.52-0.80$ (see Table I) Thus, the dark portions are poly(MA) domains and the bright portions are oligo(HEMA) domains. Consequently, membranes of the graft copolymers from G-1 to G-4 all have microdomain structures of poly(MA) spheres (island phase) dispersed in a continuous phase of oligo(HEMA) domains. With increasing MA mole fraction in the copolymer, the 
Table I. Preparation of HEMA(branch)-MA(backbone) comb type graft copolymers

\begin{tabular}{|c|c|c|c|c|c|c|}
\hline \multirow[t]{2}{*}{ Code } & \multirow{2}{*}{$\begin{array}{c}M_{n} \text { of oligo }{ }^{\mathrm{a}} \\
\quad(\text { HEMA) }\end{array}$} & \multirow{2}{*}{$\begin{array}{l}\text { Epoxide }^{\mathrm{b}} \\
\text { equivalent }\end{array}$} & \multirow{2}{*}{$\frac{\text { [Amino group }]}{\text { [Epoxy group }]}$} & \multirow{2}{*}{$\begin{array}{c}\begin{array}{c}\text { Reacting } \\
\text { conversion }\end{array} \\
\%\end{array}$} & \multirow{2}{*}{$\begin{array}{c}\begin{array}{c}\text { Grafting } \\
\text { ratio }\end{array} \\
\%\end{array}$} & \multirow{2}{*}{$\begin{array}{l}\text { MA mole fraction } \\
\text { in copolymer }\end{array}$} \\
\hline & & & & & & \\
\hline G-1 & 14600 & 1400 & 1.20 & 22.7 & 237 & 0.39 \\
\hline G-2 & 14600 & 1400 & 0.60 & 32.2 & 201 & 0.43 \\
\hline G-3 & 14600 & 1400 & 0.35 & 44.9 & 164 & 0.48 \\
\hline G-4 & 9400 & 7200 & 1.20 & 56.0 & 164 & 0.48 \\
\hline G-5 & 9400 & 4600 & 1.20 & 68.1 & 139 & 0.52 \\
\hline G-6 & 6000 & 4600 & 1.20 & 80.3 & 105 & 0.59 \\
\hline G-7 & 14600 & 1400 & 0.15 & 59.3 & 93 & 0.62 \\
\hline G-8 & 10300 & 1400 & 0.15 & 64.7 & 71 & 0.68 \\
\hline G-9 & 6000 & 1400 & 1.20 & 14.4 & 62 & 0.71 \\
\hline G-10 & 4000 & 7200 & 1.20 & 68.4 & 38 & 0.80 \\
\hline
\end{tabular}

a From amino group analysis.

b From epoxy group analysis.

c [Reacted epoxy group]/[Reactable epoxy group] $\times 100$.

d [Weight of branched oligomer (calculated from the composition)]/[Weight of backbone polymer] $\times 100$.

e From the density measurement.

Table II. Microdomain structures of graft polymeric membranes

\begin{tabular}{cccc}
\hline & \multirow{2}{*}{$\begin{array}{c}\text { MA mole fraction } \\
\text { in copolymer }\end{array}$} & \multicolumn{2}{c}{ Morphology } \\
\cline { 3 - 4 } & & PMA & OHEMA \\
\hline G-1 & 0.39 & Island & Sea \\
G-2 & 0.43 & Island & Sea \\
G-3 & 0.48 & Island & Sea \\
G-4 & 0.48 & Island & Sea \\
G-5 & 0.52 & Sea & Island \\
G-6 & 0.59 & Sea & Island \\
G-7 & 0.62 & Sea & Island \\
G-8 & 0.68 & Sea & Island \\
G-9 & 0.71 & Sea & Island \\
G-10 & 0.80 & Sea & Island \\
\hline
\end{tabular}

volume fraction of the oligo(HEMA) continuous phase decreases. Consequently, the membranes of the graft copolymers from G-5 to G-10 all have microdomain structures of oligo(HEMA) spheres (island phases) dispersed in a continuous phase of poly(MA) domains. The volume fraction of the poly(MA) continuous phase increases with increasing MA mole fraction in the copolymer. The morphology of the microdomains in the graft polymeric membranes are shown in Table II.
Selective Permeability through the Graft Polymeric Membrane

Table III shows the pervaporation characteristics of graft polymeric membranes. Figure 4 shows the relation between the MA mole fraction in the graft copolymer and the pervaporation rate. The solvents do not permeate at all through the G-2 and G-4 membranes, but do so through the other membranes. The pervaporation rate is not linearly correlated with MA mole fraction in the graft copolymer, as can be seen from Figure 4 . The rate begins to increase abruptly when the MA mole fraction exceeds 0.52 . This drastic change in the pervaporation rate is quite consistent with the change in the morphology of the membrane. The graft polymeric membranes of G-2 and G-4 have microdomain structures of poly(MA) spheres dispersed in a continuous phase of oligo(HEMA) as shown in Table II. The other membranes all have continuous phases of poly(MA) domains each volume fraction of which increases with increasing MA mole fraction in the copolymer. These results indicate that the continuous phases of poly(MA) domains in the membrane function as permeating pathways and that the pervaporation rate depends on the volume fraction of these phases.

The separation factor $\alpha$ was infinite when the solvent permeated through the membrane. The 
Table III. Summary of pervaporation characteristics through the HEMA-MA graft type membranes in a benzene-cyclohexane ( $1: 1$ by volume) mixture ${ }^{a}$

\begin{tabular}{|c|c|c|c|c|c|}
\hline \multirow[t]{2}{*}{ Membrane } & \multirow[t]{2}{*}{ MA mole fraction } & $\begin{array}{l}\text { Pervaporation } \\
\text { rate, } \mathrm{P} \times 10^{3}\end{array}$ & \multirow[t]{2}{*}{$\begin{array}{l}\text { Separation } \\
\text { factor, } \alpha\end{array}$} & \multirow[t]{2}{*}{$\begin{array}{l}\text { Solubility, } \\
\text { S }\end{array}$} & $\begin{array}{c}\text { Diffusion } \\
\text { coefficient, } \\
\mathrm{D} \times 10^{8}\end{array}$ \\
\hline & & $\mathrm{g} \mathrm{mm^{-2 }} \mathrm{h}^{-1}$ & & & $\mathrm{~cm}^{2} \mathrm{~s}^{-1}$ \\
\hline G-2 & 0.43 & 0 & - & 0.014 & 0 \\
\hline G-4 & 0.48 & 0 & - & 0.041 & 0 \\
\hline G-5 & 0.52 & 1.0 & $\infty$ & 0.196 & 1.6 \\
\hline G-7 & 0.62 & 1.6 & $\infty$ & 0.223 & 2.3 \\
\hline G-9 & 0.71 & 4.1 & $\infty$ & 0.396 & 3.3 \\
\hline G-10 & 0.80 & 7.4 & $\infty$ & 0.544 & 4.3 \\
\hline
\end{tabular}

a Experiments were carried out at $25^{\circ} \mathrm{C}$.

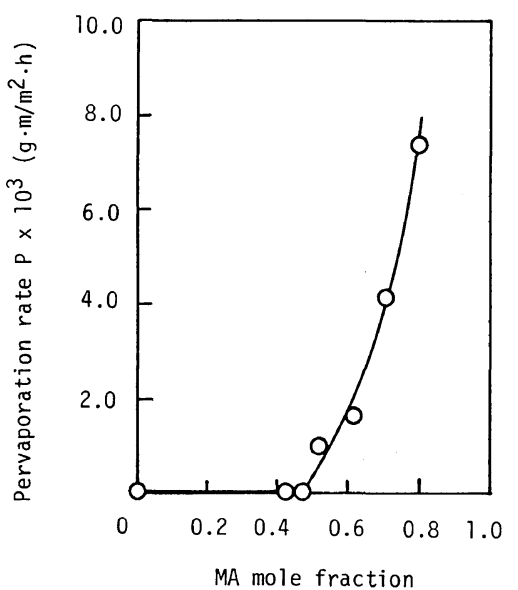

Figure 4. Pervaporation rate $v s$. composition of graft polymeric membrane in a benzene-cyclohexane $(1: 1)$ mixture at $25^{\circ} \mathrm{C}$.

continuous phases of poly(MA) domains allow benzene to preferentially permeate through the membrane. Consequently, the HEMA-MA graft polymeric membranes with the continuous phases of poly(MA) domains are effective pervaporation membranes, permitting perfect separation of azeotropic mixtures of benzene and cyclohexane.

\section{Effect of Microdomain Morphology on Sorption}

The selectivity of a membrane occurs in the sorption of the solvent into the membrane and diffusion of the solvent in the membrane. In order to understand the mechanism controlling the selective permeability of a graft polymeric membrane, it is very important to find in which of these processes

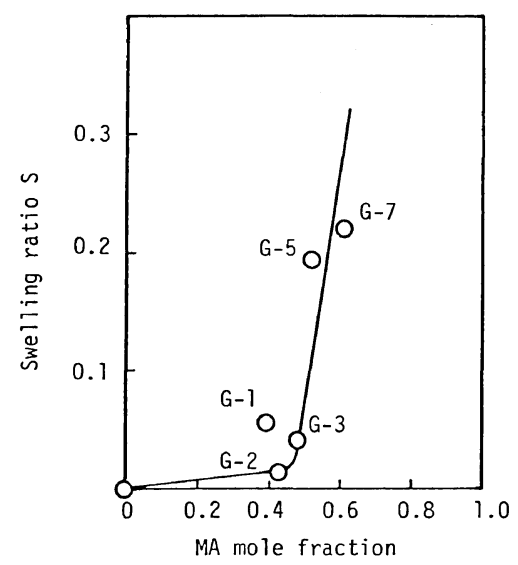

Figure 5. Weight swelling ratio vs. composition of graft polymeric membrane in a benzene-cyclohexane $(1: 1)$ mixture at $25^{\circ} \mathrm{C}$.

the selectivity occurs.

Figure 5 shows the relation between the swelling ratio in a benzene-cyclohexane (1:1 by volume) mixture at $25^{\circ} \mathrm{C}$ and the composition of a graft polymeric membrane. The swelling ratios are lower than 0.1 up to a MA mole fraction of about 0.5. Above this, the ratio abruptly increases and exceeds 0.2 . This behavior corresponds to the change in the pervaporation rate with change in the MA mole fraction in the graft copolymer, and to the morphology change in the membrane. When the poly(MA) domains are spherically dispersed in the continuous phases of oligo(HEMA) domains, the solvent are only sorbed on the surface of spherical poly(MA) domains exposed to the solvent mixture. But when the continuous phases of poly(MA) do- 
Separation of Azeotropic Mixture through Membrane

Table IV. Results of desorption experiments on a benzene-cyclohexane $\left(1: 1\right.$ by volume) mixture ${ }^{a}$

\begin{tabular}{ccccc}
\hline Membrane & MA mole fraction & $\begin{array}{c}\text { Swelling, } \\
\text { ratio }\end{array}$ & $\begin{array}{c}\text { Separation } \\
\text { factor, } \alpha_{\mathrm{s}}\end{array}$ & Morphology \\
\hline G-2 & 0.43 & 0.014 & $\infty$ & PMA Island \\
G-3 & 0.48 & 0.041 & $\infty$ & PMA Island \\
G-8 & 0.68 & 0.304 & $\infty$ & OHEMA Island \\
G-10 & 0.80 & 0.544 & $\infty$ & OHEMA Island \\
\hline
\end{tabular}

${ }^{a}$ Experiments were carried out at $25^{\circ} \mathrm{C}$.

mains are formed, the solvents sorbed on the surface of the continuous phases can easily diffuse into these.

Table IV shows the composition of the solvents sorbed into the membranes. The separation factor $\alpha_{s}$ are infinite for all membranes independent of the MA mole fraction, the microdomain structures and the swelling ratio. Benzene was found to be preferentially sorbed into the membrane, i.e., into the poly(MA) domains. This means that selectivity predominantly occurs in the process of sorption of the solvent into the membrane. It should be noted that cyclohexane is not sorbed into membranes when the MA mole fraction is high.

\section{Role of Microphase Separated Structure in Selective Permeation Membrane}

The HEMA-MA graft polymeric membranes have microphase separated structures of the constituent chains. The membrane with the continuous phases of poly(MA) domains showed a selective permeability for benzene in the benzene-cyclohexane azeotropic mixture. These phases dissolve preferentially benzene and function as permeating pathways for the selective solvent. The dissolution of non-selective solvents into the membrane does not occur even when the MA mole fraction is high. Generally, excessive swelling due to the selective solvents causes a non-selective solvent to permeate through the membrane. This is called the "plasticizing effect," and lowers the selectivity. ${ }^{11}$ Oligo(HEMA) chains having no affinity for both benzene and cyclohexane are attached to the poly(MA) backbone chain and form the spherical domains dispersed in the continuous phases of poly(MA) domains. The formation of the oligo(HEMA) domains effectively suppresses the plasticizing effect of benzene. Consequently, the perfect separation of the selective solvent can be achieved with the graft polymeric membranes.

Acknowledgment. This reseach was supported in part by Kyowa Gas Chemical Industry Co., Ltd., for which the authors should like to express their appreciation.

\section{REFERENCES}

1. J. W. Carter and B. Jagannadhhaswamy, Br. Chem. Eng., 9, 523 (1964).

2. R. Y. M. Huang and V. J. C. Lin, J. Appl. Polym. Sci., 12, 2615 (1968).

3. D. Aptel, J. Cuny, J. Jozefowicz, G. Morel, and J. Neel, J. Appl. Polym. Sci., 16, 1061 (1972).

4. I. Cabasso, J. Jagur-Grodzinski, and D. Vofsy, $J$. Appl. Polym. Sci., 18, 2137 (1974).

5. J. G. Sikonia and F. P. McCandless, J. Membr. Sci., 4, 229 (1978).

6. S. Hara and K. Mori, "Kobunshi no Kozo to Bunrikino," Kagaku Dozin, 1976.

7. S. Yoshimasu, H. Nomura, K. Komiya, T. Okano, and I. Shinohara, Nippon Kagaku Kaishi, 785 (1980).

8. S. Yoshimasu, H. Nomura, K. Komiya, J. Terada, T. Okano, and I. Shinohara, Nippon Kagaku Kaishi, 276 (1981).

9. G. L. Wilkes, J. Appl. Phys., 49, 5060 (1978).

10. T. Okano, M. Katayama, and I. Shinohara, J. Appl. Polym. Sci., 22, 369 (1978).

11. T. Hamaya and S. Yamada, Kobunshi Ronbunshu, 34, 545 (1977). 